\title{
Disposal of waste generated during drinking water disinfection with electrolytic sodium hypochlorite
}

\author{
A.Yu. Skryabin* \\ Legislative Assembly of the Rostov Region, 344050, Rostov-on-Don, Russia
}

\begin{abstract}
The present article is concerned with the problems of recycling and reuse of waste generated in the electrolytic production of sodium hypochlorite at water treatment plants. New engineering solutions aimed at ensuring environmental safety and lack of waste during large-scale production of sodium hypochlorite from aqueous solutions of common table salt are recommended herein.
\end{abstract}

\section{Introduction}

Drinking water disinfection is a mandatory step to be taken before distributing it to consumers through the water distribution system. In most cases, sanitary and epidemiological safety of water is ensured by chlorination, which is still the most common method of water disinfection in the world due to its sanitary reliability, prolonged antimicrobial effect, relative simplicity and cost effectiveness. However, the use of liquid chlorine may cause safety issues related to its transportation through populated areas and storage of large amounts at water treatment plants, many of which are already located within the expanding urban territory. The hazards of using liquid chlorine (hazard class 2) and the fact that the Vodokanal water and wastewater treatment plants fail to comply with a number of stringent industrial safety requirements of the Federal rules and regulations, in particular, "Safety Rules for Chlorine and Chlorine-Bearing Material Production" No. 554 approved by the Federal Service for Environmental, Technological and Nuclear Supervision on November 20, 2013, made the traditional technology of water disinfection ineffective. There are three possible solutions. The first is to move water treatment plants to safer areas (or to build new ones outside urban areas). Another option is to evacuate the local population outside the danger zone (in accordance with paragraph 7.1.14 of SanPiN 2.2.1/2.1.1.1200-03 "Sanitary Protection Zones and Sanitary Classification of Enterprises, Structures and Other Facilities", residential area should be at least at $500 \mathrm{~m}$ from the chlorine storage). Otherwise, a less dangerous disinfectant combining the positive qualities of chlorination and the absence of its disadvantages should be used at water treatment plants. The world experience of scientific inquiry of less dangerous disinfectants that would have the same positive qualities as chlorination but wouldn't have its negative features resulted in the idea of the beneficial economic feasibility of using a chlorine-containing

\footnotetext{
*Corresponding author: ibm2225101@gmail.com
} 
product - sodium hypochlorite $(\mathrm{NaClO})$ obtained on-site by the method of membrane-free electrolysis of an aqueous solution of common (table) salt [1-3].

In Russia, the most powerful electrolysis plants are operated using expensive imported equipment. They are located in St. Petersburg: Severnaya waterworks (3.5 tons) and Yuzhnaya waterworks (4.5 t/day of chlorine equivalent produced by NEWTEC Company); Arkhangelsk (6 GRUNDFOS/ALLDOS electrolyzers with a total capacity of $156 \mathrm{~kg} / \mathrm{day}$ of chlorine equivalent each; Ivanovo (2 GRUNDFOS plants with a total capacity of 680 kg/day); Naberezhnye Chelny (2 NST-1500 electrolysers, $680 \mathrm{~kg} /$ day, produced by Severn Trent De Nora) [4]. On the other hand, consumers of foreign technologies inevitably depend on foreign service and repair, as well as on deliveries of imported components and consumables (such as extremely expensive ruthenium-iridium coated titanium anodes with a two- or three-year warranty period for the metal oxide coating). All this causes serious financial problems and some uncertainty among importers, especially acute in view of increasing sanctions by the EU countries.

However, starting from 2008, a Russian research, scientific production company (SPC) EKOFES LLC (Novocherkassk) became a strong competitor to foreign suppliers and began developing the market for large-scale electrolysis facilities intended for production of lowconcentration sodium hypochlorite at large drinking water treatment plants.

Since the further development of the electrolysis station (facility) production was aimed at increasing their capacity, when coordinating design documents, such departments as State Project Expertise and Examination Department, Federal Environmental Supervision Service, Rosprirodnadzor and others required the $\mathrm{NaClO}$ electrolysis to be included in the general engineering plan, as well as operation of water-cleaning systems with the further recycling and reuse of industrial waste and sewage (with its further withdrawal from the inventory balance, dehydration and soluble phase recycling) generated under the following conditions:

- water conditioning (softening or decarbonization) used to dissolve salt;

- flushing saturation tanks (slurry pools);

- acid washing off cathode deposits from electrolyzers;

- flushing sand filtration plants used for fine cleaning of saturated salt solutions and distilled return water remaining from flushing of saturation tanks installed at recycling facilities.

\section{Purpose and Objectives of Research}

To develop engineering solutions and to include facilities intended for the cleaning and recycling of industrial wastewater, which is generated during the conditioning of water, salt dissolution and acid flashing of electrolyzers, in the general process flow of sodium hypochlorite production.

\section{Research Summary}

Environmental issues were first fully resolved at the most powerful electrolysis station in Russia, which was installed at Aleksandrovsky water treatment station in Rostov-on-Don, and commissioned in August 2015 [5]. By the way, it is the second largest facility in the world after Las Vegas electrolysis station with a capacity of 8 tons of active chlorine per day (7 t/day of chlorine equivalent, Fig. 1). Firstly, to eliminate the generation of wastewater discharged from Na-cationic softening plant (about $200 \mathrm{~m}^{3}$ of wastewater, backwash water, recycled water and wash water per day), instead of water softening, SPC EKOFES LLC introduced a completely waste-free and environment-friendly 
decarbonization of $3 \%$ saline solution by acidifying it with hydrochloric acid to $\mathrm{pH}=4.0$ 4.2 (bicarbonate and carbonate ions are completely converted to $\mathrm{CO}_{2}$ ) and subsequent stripping of carbon dioxide in a film degasifier with nozzle made from pall rings (residual $\mathrm{CO}_{2}$ is not more than 3-4 mg/l, Fig. 2).

Secondly, the issue of using low-quality salt (in foreign analogues only expensive salt such as Extra is used) is thus solved by using a saturation tank equipped with a water-air flushing system (similar to high-speed water filters).

A saturated saline solution is prepared by filtering tap water through a fixed bed of common salt, loaded periodically into a saturation tank onto a supporting gravel layer, inside of which a tubular drainage distribution system is installed. Water is saturated with salt during a slow filtration $(0.1-0.5 \mathrm{~m} / \mathrm{h})$ process. Particles of clay, sand and other insoluble impurities coming from salt added to the saturation tank gradually accumulate in the filtering layer and are subject to the regular removal by flushing the system with reverse water.

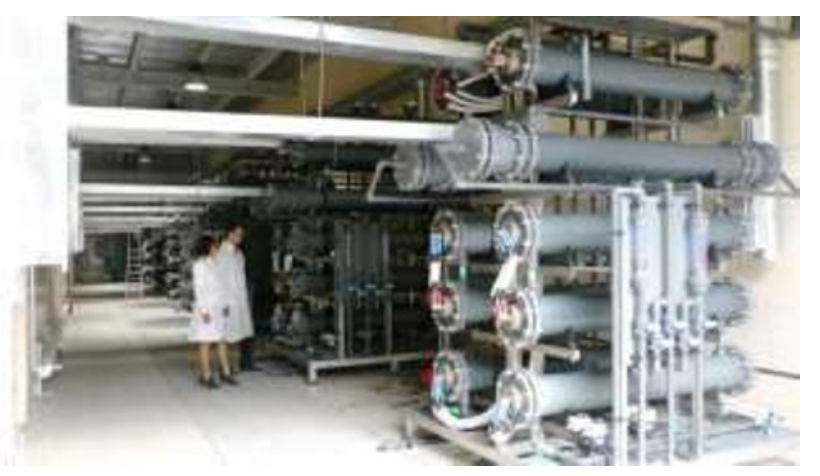

Fig. 1. Electrolysis plant at Aleksandrovsky wastewater treatment station equipped with seven HLOREFS units with a total capacity of 7 chlorine equivalent tons per day and used for the drinking water disinfection in Rostov-on-Don city.

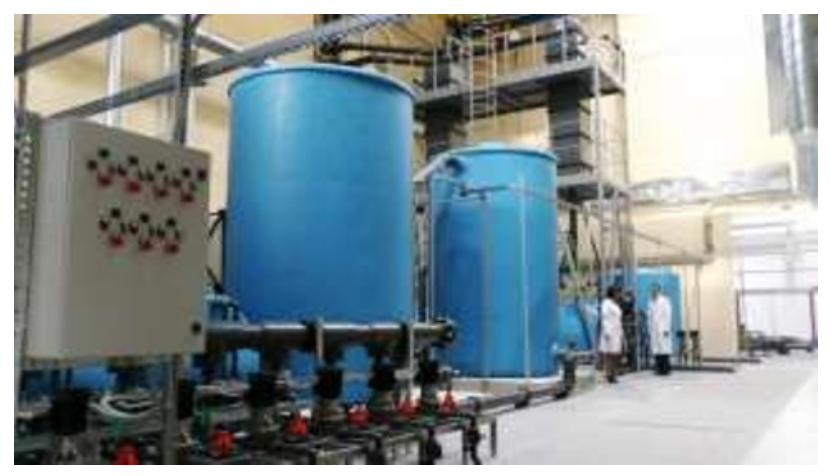

Fig. 2. Acid treatment unit used for standard salt solution decarbonization and installed at Aleksandrovskiy Wastewater Treatment Station, Rostov-on-Don

The wash water recycling facilities designed for the saturation tank look like a series of vertical sand traps and a discontinuously operated water sump. The sand is regularly removed from the sand trap pit with a sand pump feeding pulp to a sand washing machine. The washed sand is then transported into a removable container by an auger feeder.

The wash water sump is a horizontally placed rectangular tank with a bottom slope in the direction of the mud pit. 
The sediment is regularly removed from the pit by stirring it up with a flushing system. A submersible pump is used then feed it to the industrial sewage system of the wastewater treatment plant (water treatment and recycling facilities which receive wash water from high-speed filters). The separated water is taken from its upper level. The water leaving the sump is fed to a pressure sand filter (two combined filters are installed and equipped with an automatic flushing system) and then returned to the saturation tank. The filters are washed with tap water which is then discharged into the recycling facilities of the water treatment plant.

This technology provides for returning practically all the water used for washing the saturation tank, to the salt-dissolving flow chart. Note that the wash water received from the saturation tank must not be discharged into facilities not specifically designed for this purpose, for example, to the water treatment and return facilities from washing water treatment filters, due to the high $\mathrm{NaCl}$ content in such wastewater (up to $100 \mathrm{~g} / \mathrm{l}$ ).

Finally, there is one more type of wastewater that must be returned to a state which meets the requirements for admitting the water to the the industrial sewage of the water treatment plant or returning it to the electrolysis system. This wastewater is received after flushing electrolyzers with a hydrochloric acid solution. According to the Newtec technology (used at Severnaya water station (3.5 tons) and Yuzhnaya station (4.5 tons of chlorine equivalent per day) in St. Petersburg), when calcium carbonate deposits are generated on the cathode plates, electrolyzers must be periodically flushed through a closed loop with $4 \%$ hydrochloric acid solution.- An operator manages the flushing process manually by connecting a mobile unit equipped with an acid container and a circulation pump to the electrolyzer. The sources reviewed provide no information on the place in which the the waste acid should be discharged, as well as on the waste salt regeneration solutions received from Na-cationization. Most likely, they are discharged into the sewage system of the water treatment plant, which is basically unacceptable.

The electrolysis station engineering technology applied at the wastewater treatment plant of the Aleksandrovsky water supply system (Rostov-on-Don) provides for a permanently installed acid farm with a supply of 5-7\% $\mathrm{HCl}$ solution in each automatic mode for each of the seven installed electrolysers at a given time interval (100-200 h) which eliminates the "human" factor when the operator decides to flush the system. Hydrochloric acid is used for many times until it is completely neutralized. The neutral solution is then returned to the saturation tank by a pump at a low flow rate (designed 48 $1 / h$ ). Thus, the technology of preparing salt solutions for the water preparation used in the electrolysis system aimed at minimizing cathode deposits, acidic washing of cathodes at the designed station for electrolytic sodium hypochlorite production, is already installed in the largest Russian electrolysis station in Rostov-on-Don, and, unlike the imported technologies, is environment-friendly and completely waste-free with $100 \%$ use or recycled reagents used (water, salt, hydrochloric acid).

\section{Conclusion}

1. Further development of the electrolysis stations is aimed at increasing their capacity with regards to the generated active chlorine, which requires the $\mathrm{NaClO}$ electrolysis to be included in the general engineering plan, as well as operation of water-cleaning systems with the further recycling and reuse of industrial waste and sewage during water conditioning, salt dissolution and acid flushing of electrolyzers.

2. Acid decarbonization is more preferable when using a water conditioning technology, since it does not form secondary waste, and, besides, any kind of salt may be used. 
3. The use of low-quality salt is technologically feasible only if it is dissolved in saturation tanks equipped with the wash water supply and discharge systems.

4. Wash water recycling facilities, including a vertical sand trap, a water sump, a sandwashing machine and mechanical sand filters, ensure the return of practically all the water used in washing saturation tanks, into the salt-dissolving system.

5. Environmental and industrial safety issues are fully resolved in the "Hlorefs" electrolysis units manufactured by SPC EKOFES LLC (Novocherkassk) with $100 \%$ use or recycling of all reagents used (water, salt and acid).

\section{References}

1. L.N. Fesenko, V.V. Denisov, A.Yu. Scriabin, Sodium hypochlorite as a water disinfectant: production and use, monograph, SPC EKOFES LLC, South Russian State Polytechnic University, Novocherkassk: LIK Publishing agency, 2012.

2. S.V. Baranov, Decontamination stations based on membrane electrolysis units, Documents of the All-Russian seminar "Chlorine-Free Methods and Engineering Solutions for Drinking and Waste Water Disinfection", Moscow, 2008.

3. V.V. Boldyrev, Water Supply and Sanitary Engineering, 11, 21-23 (1999).

4. A.K. Kinebas, E.D. Nefedova, A.V. Bekrenev, Water Supply and Sanitary Equipment, 3, 24-29 (2010).

5. L.N. Fesenko, S.I. Ignatenko, I.V. Pchelnikov, A.Yu. Cherkesov, R.V. Fedotov, S.Yu. Bessarabov, Water Purification. Water Treatment. Water Supply, 5, 54-60 (2016). 